\title{
Subclinical Thyroid Dysfunction was not Associated with Cardiac Arrhythmias in a Cross-Sectional Analysis of the ELSA-Brasil Study
}

Kamilla Maria Araújo Brandão Rajão, ${ }^{1 \oplus}$ Antônio Luiz Pinho Ribeiro, ${ }^{2,3}{ }^{\circledR}$ Valéria Maria Azeredo Passos, ${ }^{2}$ Isabela Judith Martins Benseñor, ${ }^{40}$ Pedro Guatimosim Vidigal, ${ }^{[®}$ Cleber Pinto Camacho, ${ }^{[1}$ Maria de Fátima Haueisen Sander Diniz ${ }^{1,2}$ Serviço de Endocrinologia e Metabologia do Hospital das Clínicas da Universidade Federal de Minas Gerais (UFMG), ${ }^{1}$ Belo Horizonte, MG - Brazil Departamento de Clínica Médica da Faculdade de Medicina da Universidade Federal de Minas Gerais (FM-UFMG), ${ }^{2}$ Belo Horizonte, MG - Brazil Serviço de Cardiologia e Cirurgia Cardiovascular - Hospital das Clínicas da Universidade Federal de Minas Gerais (UFMG), ${ }^{3}$ Belo Horizonte, MG - Brazil Centro de Pesquisa Clínica e Epidemiológica da Universidade de São Paulo (USP), ${ }^{4}$ São Paulo, SP - Brazil Departamento de Propedêutica da Faculdade de Medicina da Universidade Federal de Minas Gerais (UFMG), ${ }^{5}$ Belo Horizonte, MG - Brazil Universidade Nove de Julho (UNINOVE), ${ }^{6}$ São Paulo, SP - Brazil

\begin{abstract}
Background: The association of subclinical thyroid dysfunction (STD) with cardiac arrhythmias remains controversial, particularly in the non-elderly population.
\end{abstract}

Objective: To investigate whether STD was associated with cardiac arrhythmias in a cohort of middle-aged and older adults.

Methods: Baseline data of the Longitudinal Study of Adult Health, ELSA-Brasil (35-74 years) were collected from 2008 to 2010. After exclusion of clinical hypothyroidism and hyperthyroidism, participants were categorized as euthyroidism $(\mathrm{TSH}=0.4-4.0 \mu \mathrm{U} / \mathrm{mL}$ ), subclinical hypothyroidism $(\mathrm{TSH}>4.0 \mu \mathrm{U} / \mathrm{mL} ; \mathrm{FT} 4=0.8-1.9 \mathrm{ng} / \mathrm{dL}$ ), and subclinical hyperthyroidism (TSH $<0.4 \mu \mathrm{U} / \mathrm{mL} ; \mathrm{FT} 4=0.8-1.9 \mathrm{ng} / \mathrm{dL}$ ). The prevalence rates of tachycardia $(\mathrm{HR}>100)$ and bradycardia (HR < 60), atrial fibrillation/flutter, conduction disorders, extrasystoles, low QRS voltage, prolonged QT intervals, and persistent supraventricular rhythms were compared between groups after adjusting for age, sex, comorbidities, lifestyle, body mass index and medications.

Results: The HR data of 13,341 participants (52\% female; median age, 51 years) and the electrocardiogram readings of 11,795 were analyzed; 698 participants (5.23\%) were classified as subclinical hypothyroidism, 193 (1.45\%) as subclinical hyperthyroidism, and $12,450(93.32 \%)$ as euthyroidism. The prevalence of rhythm and conduction disorders was similar, as were HR medians, even in the subgroups with TSH $<0.01 \mathrm{UI} / \mathrm{mL}$ or $>10.0 \mathrm{UI} / \mathrm{mL}$ or in older adults. Conduction disorders were less prevalent in older adults with subclinical hypothyroidism (adjusted $\mathrm{OR}=0.44 ; 95 \% \mathrm{CI} 0.24$ to 0.80 ).

Conclusion: In this large, multicenter and cross-sectional study, STD was not associated with cardiac arrhythmias, but a longitudinal assessment is necessary. (Arq Bras Cardiol. 2019; 112(6):758-766)

Keywords: Thyroid Diseases/complications; Pathologic Processes; Thyroropin (TSH); Arrhythmias, Cardiac; Adults.

\section{Introduction}

Subclinical thyroid dysfunctions (STD), which include subclinical hypothyroidism (SCHypoTh) and subclinical hyperthyroidism (SCHyperTh), are characterized by elevated or suppressed thyroid-stimulating hormone (TSH), without clinical alterations or abnormalities in thyroid hormone levels. ${ }^{1}$ Diagnosis of STD has been increasing with the dissemination of ultrasensitive TSH assays; however, the clinical repercussions of STD and the benefits associated with thyroid dysfunction screening are still the object of scientific debate, and further research is needed.

Mailing Address: Kamilla Maria Araújo Brandão Rajão •

Rua Rubens Carvalho de Andrade, 60/502. Postal Code 30575-810, Buritis,

Belo Horizonte, MG - Brazil

E-mail: kamillarajao@gmail.com

Manuscript received May 27, 2018, revised manuscript October 17, 2018, accepted October 17, 2018

DOI: 10.5935/abc.20190037
The prevalence of SCHyperTh ranges from $1 \%$ to $16 \%$ in large population-based studies, while that of $\mathrm{SCHypoTh}$ varies from $4 \%$ to $20 \%$. $^{1,2}$ Those prevalence rates can vary according to sex, age, degree of iodine sufficiency, and the TSH reference values adopted in each study. ${ }^{3}$ In Brazil, population-based studies have shown prevalence rates of SCHyperTh ranging from $2.4 \%$ in older adults ${ }^{4}$ to $6.2 \%$ in Japanese Brazilians aged $>30$ years, ${ }^{5}$ while SCHypoTh varied from $6.5 \%$ among older adults $^{4}$ to $12.3 \%$ in women aged $>35$ years. ${ }^{6}$

There is no consistent evidence of the clinical relevance of STD, particularly regarding the cardiovascular system. Although some meta-analyses and population-based cohort studies have indicated a higher cardiovascular risk and mortality associated with STD, 5,7 other studies do not corroborate those results. ${ }^{8-10}$ Regarding arrhythmias, SCHyperTh has been associated with a two- to three-fold risk of tachyarrhythmias, especially sinus tachycardia, atrial fibrillation (AF) and atrial flutter, extrasystoles, supraventricular and ventricular arrhythmias, ${ }^{11-17}$ and prolonged QT intervals (QTi). ${ }^{18}$ Fewer studies have explored the relationship between 
SCHypoTh and cardiac arrhythmias. Weak evidence, mostly in the form of case reports, suggests that SCHypoTh can lead to bradyarrhythmias, including sinus bradycardia and atrioventricular blocks, atrial arrhythmias, prolonged QTi, and severe ventricular arrhythmias. ${ }^{19,20}$ Most of the related studies have focused on older adults.

The aim of the present study was to investigate whether STD was associated with cardiac arrhythmias in a cohort of middle-aged and older adults in the baseline of the Longitudinal Study of Adult Health (ELSA-Brasil), the largest cohort of a Brazilian adult population to date.

\section{Methods}

\section{Study population}

The present investigation is a subproject of ELSA-Brasil, in which the baseline cohort comprised 15,105 civil servants aged 35-74 years from six Brazilian cities, who were enrolled between August 2008 and December 2010. The majority of participants were young adults ( $78 \%$ aged $<60$ years), with $54 \%$ female. The ELSA-Brasil protocol conforms to the ethical guidelines of the 1975 Declaration of Helsinki and was approved by the research ethics committees at all six centers. All participants provided a written informed consent. ${ }^{21}$

Participants were excluded if they were using any drugs that could interfere with TSH or free thyroxine (FT4) laboratory assays (levodopa, carbidopa, metoclopramide, haloperidol, valproic acid, propranolol, heparin, prazosin, rifampicin, carbamazepine, primidone, phenytoin, and furosemide). ${ }^{22}$ Participants with serum TSH and FT4 alterations indicating clinical thyroid dysfunction, including those with normal serum FT4 levels and TSH $>20 \mu \mathrm{U} / \mathrm{mL}$, or if they were using levothyroxine or antithyroid agents (thiamazole or propylthiouracil) were excluded. All participants who did not present exclusion criteria were included.

\section{Study protocol}

Standardized interviews were conducted with participants at their workplaces and at the research center. Clinical examinations and laboratory tests were performed according to standardized protocols developed for the study. Participants were instructed to present all medical prescriptions and medications they had used in the preceding month. ${ }^{21}$

Skin color was self-reported. Anthropometric parameters, including height and weight, were measured using standardized techniques and materials. Resting heart rate (HR) and blood pressure (BP) were measured three times, with the mean values for the second and third measurements considered for analysis. ${ }^{23}$

Standard 12-lead resting electrocardiograms (ECGs) were recorded and analyzed according to the Minnesota code criteria ${ }^{24}$ using a digital device (Atria 6100, Burdick, Cardiac Science Corporation, Bothel, WA, USA) with automated readings of HR; duration, range, and axes of $\mathrm{P}, \mathrm{QRS}$, and T waves; QT intervals, and QTC (Bazett's correction). The ECG tracings were analyzed at the ECG Reading Center of ELSA-Brasil in Minas Gerais. In total, 11,795 ECGs were available for analysis.
Blood samples were collected after an overnight fast. Participants were instructed to reschedule their appointment at the research center if they had a fever or developed any acute disease symptoms. All laboratory analyses were centralized in a single research center (University of São Paulo). ${ }^{25}$ The quality and management of data collection and storage were ensured through training sessions, certifications, and renewal of certifications of the interviewers and technicians in charge of the clinical examinations and laboratory tests of the study protocol. ${ }^{21}$

The methods, reagents, and equipment used in the assays conducted at the central laboratory were as follows: 1) TSH: immunoenzymatic bead-based technique, Siemens reagent L2KTS2, analytical sensitivity of $0.004 \mathrm{mU} / \mathrm{L}$, conducted for all participants; 2) FT4: immunoenzymatic bead-based technique, analytical sensitivity of $0.3 \mathrm{ng} / \mathrm{dL}$, only for those patients with abnormal TSH levels (both the TSH and FT4 assays were performed using a Siemens IMMULITE 2000 Immunoassay System ${ }^{\circledR}$ - Siemens Healthcare Diagnostics, Deerfield, IL, USA); 3) Total cholesterol: enzymatic colorimetric method, Siemens reagent (code 99301390); 4) Triglycerides: enzymatic colorimetric method with glycerol phosphate peroxidase according to Trinder; 5) HDL cholesterol: homogeneous enzymatic colorimetric method without precipitation; 6) LDL cholesterol: Friedewald equation for triglycerides $<400 \mathrm{mg} / \mathrm{dL}$; otherwise, measured directly using a homogeneous enzymatic colorimetric assay without precipitation; 7) Serum blood sugar: enzymatic hexokinase method; 8) Hemoglobin A1C: high-pressure liquid chromatography (HPLC), Bio-Rad D-10 Hemoglobin A1c Program (Bio-Rad Laboratories, Inc., Hercules, CA, USA). All biochemical tests were analyzed using the ADVIA 1200 Chemistry System (Siemens Healthcare Diagnostics, Deerfield, IL, USA); and 9) Chagas disease serology: ELISA method using a solid-phase microplate (CHAGATEST, Wiener Laboratorios S.A.I.C., Rosario, Argentina). ${ }^{25}$

\section{Definition of cases}

Participants were allocated into one of three groups: euthyroidism (TSH $=0.4-4.0 \mu \mathrm{U} / \mathrm{mL}$ ), SCHypoTh $(\mathrm{TSH}>4.0$ and $\leq 20 \mu \mathrm{U} / \mathrm{mL}$ with FT4 $=0.8-1.9 \mathrm{ng} / \mathrm{dL}$ ), and SCHyperTh $(\mathrm{TSH}<0.4 \mu \mathrm{U} / \mathrm{mL}$ and $\mathrm{FT} 4=0.8-1.9 \mathrm{ng} / \mathrm{dL})$. =

Abnormalities on ECG were categorized into rhythm disorders (AF and flutter: Minnesota codes 8.3.1, 8.3.2, 8.3.3, 8.3.4; supraventricular extrasystoles (SVES): 8.1.1; ventricular extrasystoles (VES): 8.1.2; persistent supraventricular rhythm: 8.4.1) and blocks or conduction disorders (complete right and left bundle branch block: 7.2.1, 7.2.2, 7.1.1, 7.1.2; incomplete right and left bundle branch block: 7.3 and 7.6; nonspecific intraventricular block: 7.4 , and atrioventricular blocks: $6.1 ; 6,2,1$; $6.2 .2 ; 6.2 .3 ; 6.3)$. The presence of long QTi (> 115\%) and low QRS complex voltage (9.1) was also investigated. ${ }^{24,26}$

Abnormalities on heart rate measured by clinical examination were classified as bradycardia (HR $<60$ or $<50$ beats per minute $[\mathrm{bpm}])$ and tachycardia (HR $>100$ or $>110 \mathrm{bpm})$.

Diabetes mellitus was defined by abnormal laboratory findings according to American Diabetes Association criteria (fasting blood glucose $\geq 126 \mathrm{mg} / \mathrm{dL}$, blood glucose levels two 
hours after a $75 \mathrm{~g}$ load of anhydrous glucose $\geq 200 \mathrm{mg} / \mathrm{dL}$, or hemoglobin $\mathrm{A} 1 \mathrm{c} \geq 6.5 \%$ ) or the use of insulin or oral/subcutaneous hypoglycemic drugs. Arterial hypertension was defined by a self-reported medical diagnosis of hypertension, use of anti-hypertensive agents, or blood pressure $\geq 140 / 90 \mathrm{mmHg}$. Dyslipidemia was defined as total serum cholesterol $\geq 200 \mathrm{mg} / \mathrm{dL}$ or triglycerides $\geq 150 \mathrm{mg} / \mathrm{dL}$ or $\mathrm{LDL}$ cholesterol $\geq 130 \mathrm{mg} / \mathrm{dL}$, or the use of hypolipidemic medication. Congestive heart failure, coronary artery disease, and chronic obstructive pulmonary disease were defined by a self-reported medical diagnosis. Chagas disease was defined by positive serology in the Chagas test - ELISA assay. Excessive alcohol use was defined as the intake of more than $140 \mathrm{~g}$ of alcohol per week for women and more than $210 \mathrm{~g}$ of alcohol per week for men.

Medications considered for statistical adjustments were those that could interfere with thyroid or cardiac function and included antiarrhythmic drugs, $\beta$-blockers other than propranolol (which had been excluded previously), $\beta 2$-agonists, adrenergic agonists and nondihydropyridine calcium channel blockers, lithium carbonate, potassium iodide, amiodarone, interferon- $\alpha$, systemic glucocorticoids, dopaminergic agonists, carbamazepine, and oxcarbazepine. ${ }^{27,28}$

\section{Statistical analysis}

The statistical analysis was performed using the STATA ${ }^{\text {TM }}$ software, v. 12.0. The data are described as medians and interquartile ranges or proportions, since they did not present a normal distribution, according to test of Shapiro-Wilk. The nonparametric tests of Mann-Whitney and Kruskal-Wallis were used to compare medians, Pearson's chi-squared and Fisher's exact tests to compare proportions, and Spearman's correlation coefficient to estimate correlations between continuous variables. Logistic regression analysis was delineated between SCHyperTh or SCHypoTh and serum TSH and FT4 levels and the presence of arrhythmias/ electrocardiographic abnormalities. Age, sex, skin color, body mass index (BMI), smoking status, excessive alcohol use, comorbidities (dyslipidemia, diabetes, hypertension, coronary disease, congestive heart failure, chronic obstructive pulmonary disease, and Chagas disease), and medication use were considered for adjustment. The $p$ value $<0.20$ was considered for the multivariate model, and statistical significance was $p<0.05$. Subgroup analyses were performed for older individuals (age 65-74 years) and those with extreme TSH values $(<0.1 \mu \mathrm{U} / \mathrm{mL}$ or $>10 \mu \mathrm{U} / \mathrm{mL})$.

\section{Results}

This study included 13,341 (88.32\%) of the 15,105 participants enrolled at the baseline of the ELSA-Brasil study. The 1,764 excluded participants are shown in Figure 1.

The profile of the participants for the overall study population categorized by thyroid function group is shown in Table 1 .

STD was found in $891(6.68 \%)$ participants, with a greater prevalence of SCHypoTh (5.23\%) over SCHyperTh (1.45\%). SCHypoTh was slightly associated with older age (odds ratio $[\mathrm{OR}] 1.03,95 \%$ confidence interval $[\mathrm{Cl}]$ 1.02-1.04), female sex (OR 1.18, 95\% Cl 1.01- 1.38), higher BMI (OR 1.03, 95\% Cl 1.01-1.04), and white skin color (OR 1.30, $95 \% \mathrm{Cl} 1.10-1.55)$ when compared to the euthyroidism. Black skin color (OR 0.56, 95\% Cl 0.41- 0.75) and smoking (OR $0.72,95 \% \mathrm{Cl} 0.56-0.94$ ) were independently and negatively correlated with SCHypoTh.

SCHyperTh was slightly associated with older age (OR 1.02, 95\% Cl 1.01-1.04), female sex (OR 1.71, 95\% Cl 1.26- 2.31), and black skin color (OR 1.61, 95\% Cl 1.11- 2.33). White skin color (OR 0.71, 95\% Cl 0.50-0.99) and non-smoking (OR $0.65,95 \% \mathrm{Cl} 0.49-0.88$ ) were independently and negatively associated with SCHyperTh. Increased BMI was associated with SCHyperTh only in the univariate analysis (OR 1.03, 95\% Cl 1.01-1.04) (Table 1).

There were no significant differences in the HR medians of participants with normal thyroid function (35-130 bpm, median 70), SCHypoTh (42.5-111 bpm, median 70; $\mathrm{p}=0.087$ ) and SCHyperTh (42-104 bpm, median 71.5, $\mathrm{p}=0.084$ ).

No correlation was found between HR and serum TSH or FT4 values, whether for the total study population or within each STD group. The multivariate linear regression indicated a relationship between TSH levels and HR in the participants with SCHypoTh ( $p=0.001$, after adjustment). No relationship was found between TSH levels and HR in the SCHyperTh group, or between FT4 levels and HR in any of the groups.

Tachycardia was found in $3.10 \%$ of the participants and was not associated with STD, even among older adults or in those with extreme TSH values, as shown in Table 2. Likewise, bradycardia $(14,72 \%)$ was not significantly associated with STD, even in those subgroups.

The relationship between TSH and FT4 levels and heart rate is shown in Table 3. Median TSH levels were significantly higher for individuals with tachycardia compared to those with normal HR, even after adjustments, and medians for FT4 levels were significantly higher in individuals with tachycardia.

Considering the 11,795 ECGs analyzed in this study, no abnormality was associated with STD (Table 4), even in the subgroup of older adults or those with extreme TSH values. The only correlation found was a lower frequency of branch blocks in older adults with SCHypoTh compared to those who were euthyroid (14.29\% vs. $26.13 \%$; adjusted OR $0.44,95 \%$ Cl 0.24-0.80; $p=0.007$ ).

A sensitivity analysis was performed excluding all participants in use of antiarrhythmic drugs, $\beta$-blockers, $\beta 2$-agonists, adrenergic agonists and nondihydropyridine, calcium channel blockers, lithium carbonate, potassium iodide, amiodarone, interferon- $\alpha$, systemic glucocorticoids, dopaminergic agonists, carbamazepine, and oxcarbazepine, and most of the results were the same, without any association between STD and abnormalities in ECG, and no correlation or relationship was found between HR and serum TSH or FT4 values, whether for the total study population or within each STD group. The only association found was the lower frequency of bradycardia $(\mathrm{HR}<60 \mathrm{bpm})$ in participants with SCHyperTh compared to those who were euthyroid $(8,23 \%$ vs. $13,54 \%$; adjusted OR $0.62,95 \% \mathrm{Cl} 0.41-0.93 ; \mathrm{p}=0.021$ ). 


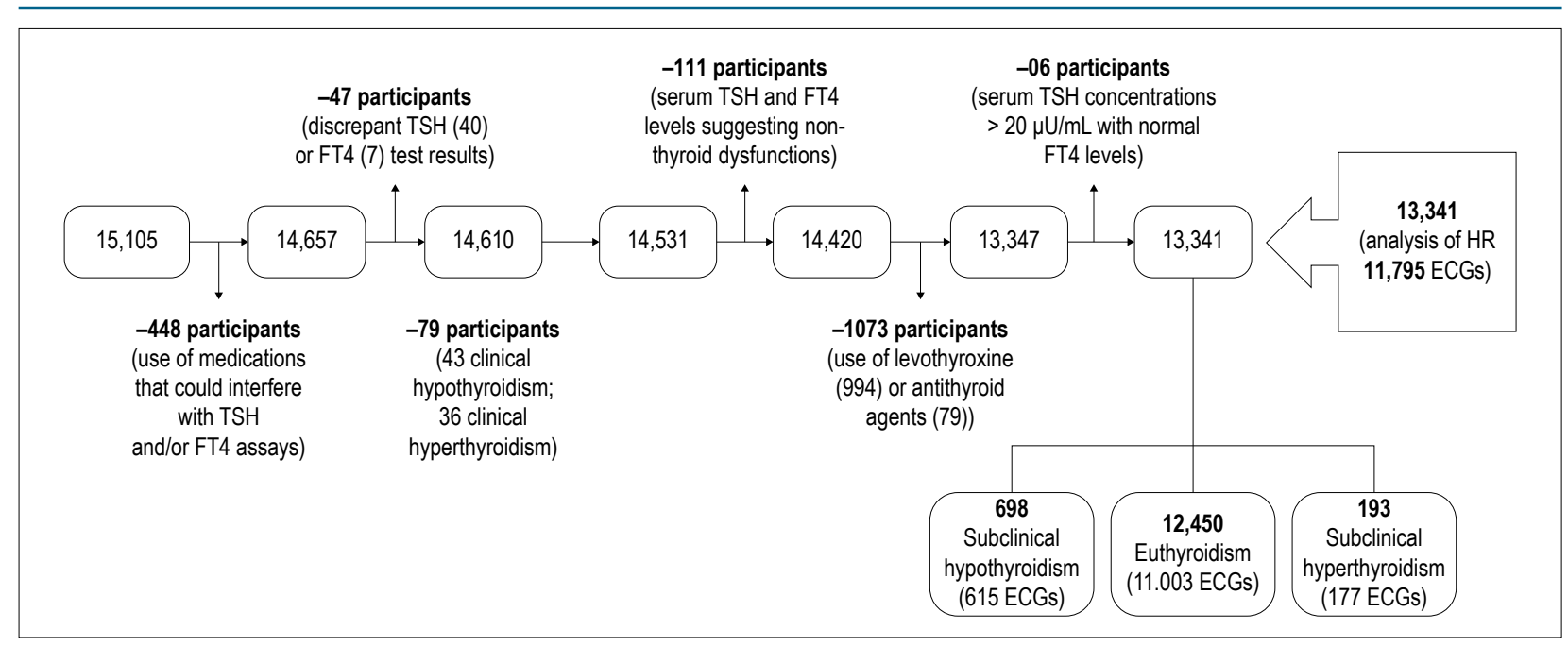

Figure 1 - Inclusion of participants from the ELSA-Brasil study baseline, 2008-2010. TSH: thyroid-stimulating hormone; FT4: free thyroxine; ECG: electrocardiogram.

Table 1 - Characteristics of participants categorized by thyroid function group, Longitudinal Study of Adult Health, ELSA-Brasil, 2008-2010

\begin{tabular}{|c|c|c|c|c|}
\hline & Subclinical hypothyroidism & Euthyroidism & Subclinical hyperthyroidism & Total \\
\hline$N(\%)$ & $698(5.23 \%)$ & $12,450(93.32 \%)$ & $193(1.45 \%)$ & $13,341(100 \%)$ \\
\hline Age, $y^{*}$ & $54(47-61) \dagger$ & $51(45-58)$ & $53(46-59) \dagger$ & $51(45-58)$ \\
\hline Female sex (\%) & $381(54.58 \%) \ddagger$ & $6,433(51.67 \%)$ & $123(63.73 \%) \ddagger$ & $6,937(52.00 \%)$ \\
\hline $\operatorname{BMI}\left(\mathrm{kg} / \mathrm{m}^{2}\right)^{*}$ & $26.80(24.03-29.96) \S$ & $26.27(23.63-29.48)$ & $26.16(23.55-29.39) \dagger$ & $26.30(23.65-29.52)$ \\
\hline Education $\geq$ completed secondary education (\%) & $589(84.38 \%)$ & $10,887(87.45 \%)$ & $163(84.46 \%)$ & $11,639(87.24 \%)$ \\
\hline \multicolumn{5}{|l|}{ Skin color (\%) } \\
\hline white & $426(61.03 \%) \S$ & $6,283(50.47 \%)$ & $72(37.30 \%) \S$ & $6,781(50.82 \%)$ \\
\hline brown & $177(25.36 \%)$ & $3,547(28.49 \%)$ & $54(27.98 \%)$ & $3,778(28.32 \%)$ \\
\hline black & $60(8.60 \%) \S$ & $2,032(16.32 \%)$ & $54(27.98 \%) \S$ & $2,146(16.09 \%)$ \\
\hline others & $35(5.01 \%)$ & $588(4.72 \%)$ & $13(6.74 \%)$ & $636(4.77 \%)$ \\
\hline Hypertension (\%) & $243(34.81 \%)$ & $4,258(34.20 \%)$ & $87(45.08 \%) \S$ & $4,588(34.39 \%)$ \\
\hline Diabetes mellitus (\%) & $145(20.77 \%)$ & $2,493(20.02 \%)$ & $46(23.83 \%)$ & $2,684(20.12 \%)$ \\
\hline Dyslipidemia (\%) & $547(78.37 \%) \dagger$ & $9,338(75.00 \%)$ & $138(71.50 \%)$ & $10,023(75.13 \%)$ \\
\hline LDL > 130 & $395(56.59 \%)$ & $7,059(56.70 \%)$ & $112(58.03 \%)$ & $7,566(56.71 \%)$ \\
\hline TGC $>150$ & $254(36.39 \%) \S$ & $3,850(30.92 \%)$ & $58(30.05 \%)$ & $4,162(31.20 \%)$ \\
\hline Coronary artery disease (\%) & $44(6.30 \%) \dagger$ & $531(4.27 \%)$ & $10(5.18 \%)$ & $585(4.39 \%)$ \\
\hline CHF $(\%)$ & $14(2.01 \%)$ & $170(1.37 \%)$ & $4(2.07 \%)$ & $188(1.41 \%)$ \\
\hline COPD (\%) & $17(2.44 \%) \dagger$ & $241(1.94 \%)$ & $6(3.11 \%)$ & $264(1.98 \%)$ \\
\hline Chagas' disease (\%) & $9(1.29 \%)$ & $112(0.90 \%)$ & $0(0.00 \%)$ & $121(0.91 \%)$ \\
\hline Excessive alcohol (\%) & $43(6.16 \%)$ & $992(7.97 \%)$ & $10(5.18 \%)$ & $1,045(7.83 \%)$ \\
\hline \multicolumn{5}{|l|}{ Smoking status } \\
\hline Current smoker & $66(9.46 \%) \S$ & $1,689(13.56 \%)$ & $38(19.69 \%) \S$ & $1,793(13.43 \%)$ \\
\hline Former smoker & $247(35.39 \%) \S$ & $3,639(29.23 \%)$ & $64(33.16 \%)$ & $3,950(29.61 \%)$ \\
\hline No smoking & $385(55.16 \%)$ & $7,122(57.21 \%)$ & $91(47.15 \%) \S$ & $7,598(56.96 \%)$ \\
\hline $\mathrm{TSH}(\mu \mathrm{U} / \mathrm{mL})$ * & $5.065(4.43-6.26) \S$ & $1.48(1.04-2.18)$ & $0.28(0.17-0.34) \S$ & $1.53(1.04-2.32)$ \\
\hline $\mathrm{FT4}(\mathrm{ng} / \mathrm{dl}){ }^{*}$ & $1.10(1.0-1.2)$ & $1.145(1.05-1.235)$ & $1.20(1.10-1.40) \S$ & $1.10(1.00-1.24)$ \\
\hline
\end{tabular}

BMI: body mass index; LDL: lipoprotein low density; TGC: triglycerides; CHF: congestive heart failure; COPD: chronic obstructive pulmonary disease; Chagas disease: positive serology in the Chagatest - ELISA assay; TSH: thyroid-stimulating hormone; FT4: free thyroxine; * Median (Interquartile range); † Statistically significant difference $(p<0.05)$ without adjustment, compared to the euthyroidism; $\neq p<0.05$ after adjustment by age; $\S p<0.05$ after adjustment by age and sex. 
Table 2 - Association between Heart Rate and Subclinical Thyroid Dysfunction, ELSA-Brasil, 2008-2010

\begin{tabular}{|c|c|c|c|c|c|c|c|}
\hline & \multicolumn{3}{|c|}{ Subclinical Hypothyroidism } & \multicolumn{2}{|c|}{ Euthyroidism } & \multicolumn{2}{|c|}{ Subclinical Hyperthyroidism } \\
\hline & Prevalence N (\%) & OR (Cl 95\%) & "p" & Prevalence N (\%) & Prevalence $\mathrm{N}(\%)$ & $\mathrm{OR}(\mathrm{Cl} 95 \%)$ & "p" \\
\hline $\begin{array}{l}\text { Tachycardia > } 100 \text { bpm } \\
413(3.10 \%)\end{array}$ & $23(3.76 \%)$ & $1.04(0.67-1.59)$ & 0.874 & $385(3.63 \%)$ & $5(2.89 \%)$ & $0.79(0.32-1.93)$ & 0.604 \\
\hline $\begin{array}{l}>110 \mathrm{bpm} \\
344(2.58 \%)\end{array}$ & $17(2.81 \%)$ & $0.91(0.56-1.50)$ & 0.715 & $323(3.07 \%)$ & $4(2.33 \%)$ & $0.75(0.28-2.04)$ & 0.576 \\
\hline $\begin{array}{l}\text { Bradycardia < } 60 \text { bpm } \\
1,964(14.72 \%)\end{array}$ & $86(12.74 \%)$ & $0.80(0.64-1.01)$ & 0.062 & $1,858(15.40 \%)$ & $20(10.64 \%)$ & $0.65(0.41-1.04)$ & 0.074 \\
\hline $\begin{array}{l}<50 \text { bpm } \\
211(1.58 \%)\end{array}$ & $12(2.00 \%)$ & $1.07(0.59-1.92)$ & 0.830 & $195(1.87 \%)$ & $4(2.33 \%)$ & $1.25(0.46-3.39)$ & 0.667 \\
\hline
\end{tabular}

Table 3 - Relationship between Heart Rate and TSH and FT4 Levels, ELSA-Brasil, 2008-2010

\begin{tabular}{lccc}
\hline & & TSH & FT4 \\
\cline { 2 - 4 } & Median $(\mu \mathrm{U} / \mathrm{ml})$ & p-value* $^{*}$ & Median (ng/dl) \\
\hline Tachycardia $(>100 \mathrm{bpm})$ & 1.63 & 0.004 & 1.20 \\
Normal HR $(60-100 \mathrm{bpm})$ & 1.52 & & 1.10 \\
Bradycardia $(<60 \mathrm{bpm})$ & 1.54 & 0.311 & 1.10 \\
\hline
\end{tabular}

TSH: thyroid-stimulating hormone; FT4: free thyroxine; HR: heart rate; *after adjustment.

Table 4 - Association between Abnormalities on the ECGs and Subclinical Thyroid Dysfunction, ELSA-Brasil, 2008-2010

\begin{tabular}{|c|c|c|c|c|c|c|c|}
\hline & \multicolumn{3}{|c|}{ Subclinical Hypothyroidism (615 ECGs) } & \multirow{2}{*}{$\begin{array}{c}\begin{array}{c}\text { Euthyroidism } \\
(11,003 \text { ECGs) }\end{array} \\
\text { Prevalence N (\%) }\end{array}$} & \multicolumn{3}{|c|}{ Subclinical Hyperthyroidism (177 ECGs) } \\
\hline & Prevalence N (\%) & OR (Cl 95\%) & "p" & & Prevalence $\mathrm{N}(\%)$ & OR (Cl 95\%) & "p" \\
\hline AF/Flutter $42(0.36 \%)$ & $2(0.33 \%)$ & $0.89(0.22-3.70)$ & 0.878 & $40(0.36 \%)$ & $0(0 \%)$ & ----------------- & 0.422 \\
\hline $\begin{array}{l}\text { Persistent supraventricular } \\
\text { rhythm } 89(0.75 \%)\end{array}$ & $5(0.81 \%)$ & $1.08(0.44-2.67)$ & 0.870 & $83(0.75 \%)$ & $5(1.69 \%)$ & $0.75(0.10-5.40)$ & 0.773 \\
\hline $\begin{array}{l}\text { Long QT interval } \\
334(2.83 \%)\end{array}$ & $15(2.15 \%)$ & $0.85(0.50-1.43)$ & 0.532 & $315(2.53 \%)$ & $4(2.07 \%)$ & $0.82(0.30-2.21)$ & 0.688 \\
\hline LV QRS 166 (1.41\%) & $10(1.63 \%)$ & $1.16(0.61-2.22)$ & 0.644 & $154(1.40 \%)$ & $2(1.13 \%)$ & $0.81(0.20-3.27)$ & 0.762 \\
\hline $\begin{array}{l}\text { Conduction disorders } \\
2,067(17.52 \%)\end{array}$ & $101(16.42 \%)$ & $0.92(0.74-1.14)$ & 0.437 & $1,942(17.65 \%)$ & $24(13.56 \%)$ & $0.73(0.47-1.13)$ & 0.158 \\
\hline
\end{tabular}

AF: atrial fibrillation; LV QRS: Low QRS voltage; ECGs: electrocardiograms.

\section{Discussion}

This cross-sectional analysis of 13,341 individuals of this Brazilian cohort found no association of STD with HR, rhythm alterations, or conduction disorders, which suggests a limited influence of STD on cardiac rhythm and conduction. The only association found was an unexpected lower frequency of conduction disorders among the older participants with SCHypoTh compared to euthyroid participants, and it may be due to some unknown confounding factor not estimated or controlled for.

Of note, no population-based study has assessed the association between electrocardiographic abnormalities such as conduction disorders, low QRS complex voltage, prolonged QTi, and persistent supraventricular rhythms and the presence of STD, particularly SCHypoTh. Most of the studies on this subject are case reports or relate those abnormalities to clinical, rather than subclinical, hypothyroidism.

There is a paucity of studies on the prevalence of cardiac arrhythmias in the general population, without known heart disease or comorbidities, and most of those available address older individuals in developed countries. This prevalence varies according to the type of arrhythmia, age, sex, presence of structural heart disease or cardiovascular risk factors, and the diagnostic method employed. ${ }^{29,30} \mathrm{AF}$ was found in $0.35 \%$ of the participants in the present study, which is a similar result to those of population-based studies showing prevalence rates of $0.2 \%$ to $1.0 \% .^{28,30-32}$ However, considering that the prevalence of AF can be as high as $10 \%$ in individuals aged 70 years or older, ${ }^{32}$ the frequency of $\mathrm{AF}$ and flutter was low $(1.32 \%)$ among older adults in this study. 


\section{Original Article}

Table 5 - Comparison between Previous Studies and ELSA-Brasil Results, 2008-2010

\begin{tabular}{|c|c|c|c|c|c|}
\hline \multicolumn{6}{|c|}{ Consistent Findings } \\
\hline \multicolumn{6}{|c|}{ Cross-Sectional Analysis: } \\
\hline Study/Author & Population & Design/enrollment & TSH level $(\mu \mathrm{U} / \mathrm{mL})$ & $\begin{array}{l}\text { Ascertainment } \\
\text { of Events }\end{array}$ & Results \\
\hline $\begin{array}{l}\text { Cappola } 2006 \\
\text { (Cardiovascular Health } \\
\text { Study, USA) }\end{array}$ & $\begin{array}{l}\text { 3,233 elderly people } \\
\text { (mean age } 72.7 \text { years) }\end{array}$ & $\begin{array}{l}\text { Population-based prospective } \\
\text { cohort study }\end{array}$ & $0.45-4.5$ & ECG & $\begin{array}{l}\text { No difference in AF } \\
\text { prevalence between } \\
\text { SCHyperTh and } \\
\text { euthyroidism groups ( } 8.5 \% \\
\text { vs. } 5.2 \% \text {. } p>0.05 \text { ) }\end{array}$ \\
\hline \multicolumn{6}{|l|}{ Longitudinal analysis: } \\
\hline $\begin{array}{l}\text { Nanchen } 2012 \\
\text { (PROSPER Trial, Netherlands, } \\
\text { Scotland and Ireland) }\end{array}$ & $\begin{array}{l}5,316 \text { elderly people } \\
\text { (mean age } 75 \text { years) }\end{array}$ & $\begin{array}{l}\text { prospective cohort study; } \\
\text { outpatients of centers study }\end{array}$ & $0.45-4.5$ & ECG & $\begin{array}{l}\text { No difference in AF } \\
\text { incidence between } \\
\text { SCHypoTh, SCHyperTh } \\
\text { and euthyroidism groups in } \\
3.5 \text { years follow-up }\end{array}$ \\
\hline \multicolumn{6}{|c|}{ DISCORDANT FINDINGS } \\
\hline \multicolumn{6}{|c|}{ Cross-sectional analysis } \\
\hline Auer 2001 (Austria) & $\begin{array}{c}\text { 23,838 patients (median } \\
67.9 \text { years old) }\end{array}$ & $\begin{array}{l}\text { Cross-sectional } \\
\text { Patients admitted in a hospital }\end{array}$ & $0.4-4.0$ & ECG & $\begin{array}{l}\text { Higher AF prevalence in } \\
\text { SCHyperTh }(12.7 \% \text { vs. } \\
2.3 \% \text {. OR adjusted } 2.8 \\
\text { CI95\% 1.3-5.8) }\end{array}$ \\
\hline Gammage 2007 (England) & $\begin{array}{l}\text { 5,860 elderly people } \\
\text { (median } 72 \text { years old) }\end{array}$ & $\begin{array}{l}\text { Cross-sectional; Primary } \\
\text { care service }\end{array}$ & $0.4-5.5$ & ECG & $\begin{array}{c}\text { Higher AF prevalence in } \\
\text { SCHyperTh ( } 9.5 \% \text { vs. } 4.7 \% \text {. } \\
\text { OR adjusted } 1.89 \text { Cl95\% } \\
1.01-3.57)\end{array}$ \\
\hline $\begin{array}{l}\text { Vadiveloo } 2011 \\
\text { (TEARS, Scotland) }\end{array}$ & $\begin{array}{l}2,004 \text { cases (mean } \\
\text { age } 66.5 \text { years) and } \\
10,111 \text { controls }\end{array}$ & $\begin{array}{l}\text { Retrospective; Tayside } \\
\text { health registry }\end{array}$ & $0.4-4.0$ & ECG/ Holter & $\begin{array}{c}\text { Higher arrhythmia } \\
\text { frequency in SCHyperTh } \\
(2.7 \% \text { vs. } 1.4 \% . p<0.001)\end{array}$ \\
\hline
\end{tabular}

TSH: thyroid-stimulating hormone; ECG: electrocardiogram; SCHyperTh: subclinical hyperthyroidism; SCHypoTh: subclinical hypothyroidism; AF: atrial fibrillation.

Most longitudinal studies, ${ }^{9,12,17,33-35}$ but not all, ${ }^{36}$ have found AF to be associated with SCHyperTh. However, that association differs between cross-sectional studies. Interestingly, no participant with SCHyperTh in the present study manifested AF/atrial flutter. In line with this study, Cappola et al. showed no association between AF and STD at the baseline assessment of a community cohort of 2,639 older adults (mean age, 72.7 years). ${ }^{9}$ In contrast, Auer et al. reviewed the data of 23,838 individuals admitted to a hospital in Austria and found a prevalence rate of $12.7 \%$ for AF among the 613 patients (mean age, 67.9 years) with SCHyperTh (adjusted OR, 2.8; 95\% Cl 1.3-5.8), but the tests were not performed at a single laboratory. ${ }^{15}$ In a study by Gammage et al., the prevalence of $\mathrm{AF}$ was $9.5 \%$ among individuals with SCHyperTh in a cohort of 5,860 primary care patients with a median age of 72 years (adjusted OR, 1.89; $95 \% \mathrm{Cl} 1.01-3.57)$, however, the TSH levels adopted to define euthyroidism were higher $(5.5 \mu \mathrm{U} / \mathrm{mL}) .^{16}$

The prevalence of extrasystoles in the present study was also low $(0.66 \%$ for SVES and $0.13 \%$ for VES), compared to the prevalence of VES in the $\mathrm{HCHS} / \mathrm{SOL}$ study $(0.98 \%$ in men and $0.53 \%$ in women). ${ }^{29}$ In general, the prevalence rates of the other arrhythmias were similar to those found in the aforementioned studies. No association was noted between SVES or VES and STD, and no differences were detected in HR means between the groups in the present study. Vadiveloo et al. demonstrated in baseline data a greater prevalence of arrhythmias among the participants with SCHyperTh $(2.7 \%$ vs. $1.4 \%, p<0.001)$, although there was a higher frequency of preexisting cardiovascular disease in their cohort. ${ }^{17}$

In the present study, higher FT4 medians were identified in participants with tachycardia, albeit still within the normal range, which could be explained by the physiological effect of the thyroid hormone on cardiac chronotropism. ${ }^{37}$ Gammage et al. found similar results, with a positive and direct correlation between FT4 levels and a tachyarrhythmia (AF) in their cross-sectional study. ${ }^{16}$ Surprisingly, higher TSH medians were also associated with tachycardia after adjustment for potential confounding factors, but the probable mechanism for this association is unknown.

It can be speculated that STD may result in greater electrocardiographic repercussions only in specific populations with more severe comorbidities. In the ELSA population, a lower median age (51 years) and the smaller prevalence of comorbidities than in the populations recruited in cardiology or emergency services, can explain the discrepancies in relation to previous studies, which may also be due to the different TSH thresholds used to define SCHypoTh (4.5 to $5.5 \mu \mathrm{U} / \mathrm{mL}$ vs. $4.0 \mu \mathrm{U} / \mathrm{mL}$ ). ${ }^{9,12,16}$ The findings of the most relevant studies reporting concordant or discordant results with those of the present study are summarized in Table 5. 
In line with previous studies, ${ }^{1,2,13} \mathrm{SCHypoTh}$ was more frequent than SCHyperTh in the current study $(5.23 \%$ vs. $1.45 \%)$. As expected, SCHypoTh was more frequent with increasing age, female sex, higher BMI, and white skin color. In contrast, SCHypoTh was negatively associated with black skin color and current smoking. ${ }^{1,2,6}$ SCHyperTh showed a positive and independent association with increasing age, female sex, and black skin color, which are also consistent with population-based studies. ${ }^{3,6}$

The strengths of the present study were the large multicenter samples, the methodological rigor in recruiting and data collection, and the centralized analysis of the laboratory tests and ECGs. The cohort was composed of volunteers, mostly middle-aged individuals, recruited outside of the hospital and evaluated in the absence of any acute illness, which most likely excluded non-thyroid diseases. The limitations of this study include the following: TSH was measured only once; FT4 concentrations were measured only for those participants with abnormal TSH levels, and a single ECG was used for the diagnosis of arrhythmias; and no other laboratory, clinical, or ecographic data were available to assess whether the laboratory test abnormalities indeed correspond to STD. This limitation should be kept in mind, especially considering the TSH medians that indicated mild STD. Not all of the ECGs were available for analysis, however the mean age of the participants whose ECGs were analyzed was greater than that of the total cohort sample, which might in fact overestimate the overall prevalence of arrhythmias e corroborates the lack of association with STD. Only 33 of the participants had TSH $>10 \mu \mathrm{U} / \mathrm{mL}(4.73 \%$ of SCHypoTh) while 35 showed TSH $<0.1 \mu \mathrm{U} / \mathrm{mL}(18.13 \%$ of SCHyperTh). Moreover, some ECG abnormalities were rather uncommon, as rhythm disorders, with a prevalence of less than $1 \%$. Therefore, the statistical power to identify associations between those subgroups and rhythm and conduction alterations may have been insufficient. A longitudinal assessment is needed to determine the incidence of arrhythmias as well as their relative risk for each of the STD groups.

\section{Conclusion}

The present study provides contrary evidence to the association between electrocardiographic changes and STD in a seemingly healthy non-elderly population. Although, given the limitations inherent to a cross-sectional analysis, the lack of this association cannot be definitively excluded at this point, and a longitudinal assessment is needed.

\section{Author contributions}

Conception and design of the research: Ribeiro ALP, Rajão KMAB, Passos VMA, Benseñor IJM, Diniz MFHS; Acquisition of data: Ribeiro ALP, Passos VMA, Benseñor IJM, Vidigal PG; Analysis and interpretation of the data and Critical revision of the manuscript for intellectual content: Ribeiro ALP, Rajão KMAB, Passos VMA, Benseñor IJM, Vidigal PG, Camacho CP, Diniz MFHS; Statistical analysis and Writing of the manuscript: Rajão KMAB, Passos VMA, Camacho CP, Diniz MFHS; Obtaining financing: Passos VMA, Benseñor IJM,.

\section{Potential Conflict of Interest}

No potential conflict of interest relevant to this article was reported.

\section{Sources of Funding}

This study was funded by Departamento de Ciência e Tecnologia do Ministério da Saúde do Brasil (Decit); Ministério da Ciência, Tecnologia e Inovação; CNPq e FINEP.

\section{Study Association}

This article is part of the thesis of master submitted by Kamilla Maria Araújo Brandão, from Universidade Federal de Minas Gerais - UFMG

\section{Ethics approval and consent to participate}

This study was approved by the Ethics Committee of theFaculdade Federal de Minas Gerais under the protocol number ETIC 186/06. All the procedures in this study were in accordance with the 1975 Helsinki Declaration, updated in 2013. Informed consent was obtained from all participants included in the study.

\section{References}

1. Vanderpump M, Tunbridge WM, French JM, Appleton D, Bates D, Clark F, et al. The incidence of thyroid disorders in the community: a twenty-year follow-up of the Whickham Survey. Clin Endocrinol. 1995;43(1):55-68.

2. Canaris GJ, Manowitz NR, Mayor G, Ridgway EC. The Colorado thyroid disease prevalence study. Arch Intern Med. 2000;160(4):526-34.

3. Donangelo I, Braunstein G. Update on subclinical hyperthyroidism. Am Fam Physician. 2011;83(8):933-8.

4. Benseñor IM, Goulart AC, Lotufo PA, Menezes PR, Scazufca M. Prevalence of thyroid disorders among older people: results from the São Paulo Ageing \& Health Study. Cad Saude Publica. 2011;27(1):155-61.

5. Sgarbi JA, Matsumura LK, Kasamatsu TS, Ferreira SR, Maciel RM. STDs are independent risk factors for mortality in a 7.5-year follow-up: the JapaneseBrasilian thyroid study. Eur J Endocrinol. 2010;162(3):569-77.

6. Sichieri R, Baima J, Marante T, de Vasconcellos MT, Moura AS, Vaisman M. Low prevalence of hypothyroidism among black and Mulatto people in a population-based study of Brazilian women. Clin Endocrinol. 2007;66(6):803-7.

7. Selmer C, Olesen JB, Hansen ML, von Kappelgaard LM, Madsen JC Hansen PR, et al. Subclinical and overt thyroid dysfunction and risk of allcause mortality and cardiovascular events: a large population study. J Clin Endocrinol Metab. 2014;99(7):2372-82. 
8. Ochs N, Auer R, Bauer DC, Nanchen D, Gussekloo J, Cornuz J, et al. Metaanalysis: Subclinical Thyroid Disfunction and the risk for coronary heart disease and mortality. Ann Intern Med. 2008;148(11):832-45.

9. Cappola AR, Fried LP, Arnold AM, Danese MD, Kuller LH, Burke GL, et al. Thyroid status, cardiovascular risk, and mortality in older adults. JAMA. 2006;295(9):1033-41.

10. Waring AC, Arnold AM, Newman AB, Bùzkova P, Hirsch C, Cappola AR. Longitudinal changes in thyroid function in the oldest old and survival: the cardiovascular health study all-stars study. J Clin Endocrinol Metab. 2012;97(11):3944-50.

11. Kaminski G, Makowski K, Michałkiewicz D, Kowal J, Ruchala M, Szczepanek E, et al. The influence of subclinical hyperthyroidism on blood pressure, heart rate variability, and prevalence of arrhythmias. Thyroid. 2012;22(5):454-60.

12. Sawin CT, Geller A, Wolf PA, Belanger AJ, Baker E, Bacharach P, et al. Low serum thyrotropin concentrations as a risk factor for atrial fibrillation in older persons. N Engl J Med. 1994;331(19):1249-52.

13. Biondi B, Palmieri EA, Fazio S, Cosco C, Nocera M, Saccà L, et al. Endogenous subclinical hyperthyroidism affects quality of life and cardiac morphology and function in young and middle-aged patients. J Clin Endocrinol Metab. 2000;85(12):4701-5

14. Petretta M, Bonaduce D, Spinelli L, Vicario ML, Nuzzo V, Marciano F, et al. Cardiovascular haemodynamics and cardiac autonomic control in patients with subclinical and overt hyperthyroidism. Eur J Endocrinol. 2001;145(6):691-6.

15. Auer J, Scheibner P, Mische T, Langsteger W, Eber O, Eber B. Subclinical hyperthyroidism as a risk factor for atrial fibrillation. Am Heart J. 2001;142(5):838-42.

16. Gammage MD, Parle JV, Holder RL, Roberts LM, Hobbs FD, Wilson S, et al. Association between serum free thyroxine concentration and atrial fibrillation. Arch Intern Med. 2007;167(9):928-34.

17. Vadiveloo T, Donnan P, Cochrane L, Leese GP. The Thyroid Epidemiology, Audit, and Research Study (TEARS): morbidity in patients with endogenous subclinical hyperthyroidism. J Clin Endocrinol Metab. 2011;96(5):1344-51.

18. Owecki M, Michalak A, Nikisch E, Sowinski J. Prolonged ventricular repolarization measured by corrected QT interval (QTc) in subclinical hyperthyroidism. Horm Metab Res. 2006;38(1):44-7.

19. Biondi B, Palmieri E, Lombardi G, Fazio S. Subclinical hypothyroidism and cardiac function. Thyroid. 2002;12(6):505-10.

20. Sarma JS, Venkataraman K, Nicod P, Polikar R, Smith J, Schoenbaum MP, et al. Circadian Rhythmicity of rate-normalized QT interval in hypothyroidism and its significance for development of class III antiarrhythmic agents. Am J Cardiol. 1990;66(12):959-63.

21. Aquino EM, Barreto SM, Benseñor IM, Carvalho MS, Chor D, Duncan BB, et al. Brazilian Longitudinal Study of Adult Health (ELSA-Brasil): objectives and design. Am J Epidemiol. 2012;175(4):315-24.
22. Kailajärvi M, Takala T, Grönros P, Tryding N, Viikari J, Irjala K, etal. Reminders of drug effects on laboratory tests results. Clin Chem. 2000;46(9):1395-400.

23. Mill JG, Pinto K, Griep RH, Goulart A, Foppa M, Lotufo PA, et al. Medical assessments and measurements in ELSA-Brasil. Rev Saude Publica. 2013;47(Suppl 2):54-62.

24. Prineas RJ, Crow RS, Blackburn HW. The Minnesota Code Manual of Electrocardiographic Findings: standards and procedures for measurement and classification. Boston, MA: John Wright; 1982.

25. Fedeli LG, Vidigal PG, Leite CM, Castilhos CD, Pimentel RA, Maniero VC, et al. Logistics of collection and transportation of biological samples and the organization of the central laboratory in the ELSA-Brasil. Rev Saude Publica. 2013;47(Suppl 2):63-71.

26. Pinto- Filho MM, Brant LCC, Padilha-da-Silva JL, Foppa M, Lotufo PA, Mill $\mathrm{JG}$, et al. Electrocardiographic Findings in Brazilian Adults without Heart Disease: ELSA-Brasil. Arq Bras Cardiol. 2017; 109(5):416-24.

27. Haugen BR. Drugs that suppress TSH or cause central hypothyroidism. Best Pract Res Clin Endocrinol Metab. 2009;23(6):793-800.

28. Carvalho GA, Perez CLS, Ward LS. The clinical use of thyroid function tests. Arq Bras Endocrinol Metab. 2013;57(3):193-204.

29. Denes P, Garsides DB, Lloyd-Jones D, Gouskova N, Soliman EZ, Ostfeld R, et al. Major and minor electrocardiographic abnormalities and their association with underlying cardiovascular disease and risk factors in Hispanics/Latinos (from the Hispanic Community Health Study/Study of Latinos). Am J Cardiol. 2013;112(10):1667-75.

30. Pinto-Filho MM, Brant LCC, Foppa M, Garcia-Silva KB, Mendes de Oliveira RA, de Jesus Mendes da Fonseca M, etal. Major Electrocardiographic Abnormalities According to the Minnesota Coding System Among Brazilian Adults (from the ELSA-Brasil Cohort Study). Am J Cardiol. 2017;119(12):2081-87.

31. Ribeiro AL, Marcolino MS, Prineas RJ, Lima-Costa MF. Electrocardiographic abnormalities in elderly Chagas disease patients: 10-year follow-up of the Bambui Cohort Study of Aging. J Am Heart Assoc. 2014;3(1):e000632.

32. Camm AJ, Obel OA. Epidemiology and mechanism of atrial fibrillation and atrial flutter. Am J Cardiol. 1996;78(8A):3-11.

33. Collet TH, Gussekloo J, Bauer DC, den Elzen WP, Cappola AR, Balmer P, et al. Subclinical hyperthyroidism and the risk of coronary heart disease and mortality. Arch Intern Med. 2012;172(10):799-809.

34. Heeringa J, Hoogendoorn EH, van der Deure WM, Hofman A, Peeters RP, Hop WC, et al. High-normal thyroid function and risk of atrial fibrillation: the Rotterdam study. Arch Intern Med. 2008;168(20):2219-24.

35. Selmer C, Olesen JB, Hansen ML, Lindhardsen J, Olsen AM, Madsen JC, et al. The spectrum of thyroid disease and risk of new onset atrial fibrillation: a large population cohort study. BMJ. 2012 Nov 27;345:e7895.

36. Nanchen D, Gussekloo J, Westendorp RG, Stott DJ, Jukema JW, Trompet S, et al. Subclinical thyroid dysfunction and the risk of heart failure in older persons at high cardiovascular risk. J Clin Endocrinol Metab. 2012;97(3):852-61 .

37. Davis PJ, Davis FB. Nongenomic actions of thyroid hormone on the heart. Thyroid. 2002;12(6):459-66. 
